\title{
Outcomes of Tricuspid Valve Detachment for Isolated Ventricular Septal Defect Closure
}

\author{
John Schittek ${ }^{1, *}$ Jörg S. Sachweh ${ }^{1, *}$ Florian Arndt ${ }^{2}$ \\ Rainer Kozlik-Feldmann ${ }^{2}$ Daniel Biermann ${ }^{10}$ \\ ${ }^{1}$ Surgery for Congenital Heart Disease, University Medical Center \\ Hamburg-Eppendorf, University Heart \& Vascular Center Hamburg, \\ Hamburg, Germany \\ 2 Department for Pediatric Cardiology, University Medical Center \\ Hamburg-Eppendorf, University Heart \& Vascular Center Hamburg, \\ Hamburg, Germany
}

Thorac Cardiovasc Surg 2021;69:e48-e52.
Maria Grafmann ${ }^{2}$ Ida Hüners ${ }^{1}$

Address for correspondence Daniel Biermann, MD, Surgery for Congenital Heart Disease, University Medical Center HamburgEppendorf, University Heart \& Vascular Center Hamburg, Martinistr. 52, 20246 Hamburg, Germany (e-mail: d.biermann@uke.de).

\begin{abstract}
Keywords

- pediatric

- congenital heart disease

- outcomes

Partial detachment of the septal and anterior leaflets of the tricuspid valve (TV) is a technique to visualize a perimembranous ventricular septal defect (VSD) for surgical closure in cases where the VSD is obscured by TV tissue. However, TV incision bears the risk of causing relevant postoperative TV regurgitation and higher degree atrioventricular (AV) block. A total of 40 patients were identified retrospectively in our institution who underwent isolated VSD closure between January 2013 and August 2015. Visualization of the VSD was achieved in 20 patients without and in 20 patients with additional partial detachment of the TV. The mean age of patients with partial tricuspid valve detachment (TVD) was $0.7 \pm 0.1$ years compared with $1 \pm 0.3$ years $(p=0.22)$ of patients without TVD. There was no difference in cardiopulmonary bypass time between patients of both groups ( $123 \pm 11$ vs. $103 \pm 5$ minutes, $p=0.1)$. Crossclamp time was longer if the TV was detached ( $69 \pm 5$ vs. $54 \pm 4$ minutes, $p=0.023$ ). There was no perioperative mortality. Echocardiography at discharge and after 2.5 years ( 2 months -6 years) of follow-up showed neither a postoperative increase of tricuspid regurgitation nor any relevant residual shunt. Postoperative electrocardiograms were normal without any sign of higher degree AV block. TVD offers enhanced exposure and safe treatment of VSDs. It did not result in higher rates of TV regurgitation or relevant AV block compared with the control group.
\end{abstract}

\section{Introduction}

Along with bicuspid aortic valves, the isolated ventricular septal defect (VSD) is the most common lesion in congenital heart disease with a prevalence of 2.62 per 1,000 births. ${ }^{1}$ In

These authors contributed equally to this work.

received

March 4, 2021

accepted after revision

May 13, 2021
DOI https://doi.org/ 10.1055/s-0041-1735457. ISSN 0171-6425. fetal life, an interventricular communication is part of normal circulation. Failure to close the opening between the ventricles leads to perimembranous defects, the most common morphology of VSD. Some VSDs close spontaneously within the first year of life, though large defects always require surgical intervention. ${ }^{2}$ In 1952, Muller and Dammann introduced palliation of the defect by placement of a
C 2021. The Author(s).

This is an open access article published by Thieme under the terms of the Creative Commons Attribution-NonDerivative-NonCommercial-License, permitting copying and reproduction so long as the original work is given appropriate credit. Contents may not be used for commercial purposes, or adapted, remixed, transformed or built upon. (https://creativecommons.org/ licenses/by-nc-nd/4.0/) Georg Thieme Verlag KG, Rüdigerstraße 14, 70469 Stuttgart, Germany 
pulmonary artery band, ${ }^{3}$ thus preventing pulmonary overcirculation, heart failure, or hypertensive pulmonary vascular disease. Surgical closure was first performed in 1955 by Lillehei et al using cross circulation. ${ }^{4}$ Since then, there have been significant changes in surgical strategy and in the current era, excellent short- and long-term results are reported. Nevertheless, the entire exposure of the VSD may be obscured by chordal attachments of the tricuspid valve (TV). For better visualization and thus to avoid residual VSD, Hudspeth et al described a temporary detachment of the septal leaflet of the TV. ${ }^{5}$ Russell et al published their longterm experience of radial incision as a method to expose the defect. ${ }^{6}$ Due to the advantages of good exposure on one side and the concerns regarding TV function and possible damage to the conduction system on the other side, this technique is still a matter of debate. In this comparative study, we retrospectively evaluated the tricuspid valve detachment (TVD) technique versus the regular exposure without detachment of the septal leaflet.

\section{Patients and Methods}

Between January 2013 and September 2015, 40 consecutive patients with isolated VSD were operated on in our institution. For the study, the authors obeyed to the Declaration of Helsinki. Medical records were analyzed retrospectively and anonymously. The local ethics committee waived approval of the study (WF-063/20). Most recent findings were obtained by the outpatient department or by the referring pediatric cardiologist. Patients with concomitant procedures except for patent ductus arteriosus ligation, repair of atrial septal defect, or patent foramen ovale closure were excluded. Twenty patients (50\%) had TVD. Operative records were analyzed to identify the technique and length of operation time. Two-dimensional color Doppler echocardiographic data were reviewed from the medical record. All patients received a preoperative and a discharge echocardiogram and electrocardiogram at our hospital. Follow-up echocardiograms and electrocardiograms were also obtained from the referring cardiologists. Characterization of the degree of TV insufficiency, the degree of residual VSD and the ventricular function as demonstrated on the echocardiograms, was based on the judgment of the interpreting cardiologist as well as on the recommended criteria of the American Society of Echocardiography. ${ }^{7}$ The degree of tricuspid regurgitation (TR) was subdivided into: $0=$ none or trivial; $1=$ mild; and $2=$ moderate. None of the patients had severe regurgitation.

\section{Operative Technique}

Surgical VSD closure was performed by either of two surgeons. In our facility, isolated VSDs were approached through a median sternotomy followed by initiation of cardiopulmonary bypass $(\mathrm{CPB})$ using aortic and bicaval cannulation with moderate hypothermia $\left(28-32^{\circ} \mathrm{C}\right)$. For myocardial preservation, cold crystalloid cardioplegia was used (Bretschneider cardioplegic solution $30 \mathrm{~mL} / \mathrm{kg}$ body weight). After incision of the right atrium, the septal leaflet of the TV was retracted (-Fig. 1A). If the defect was exposed clearly, a standard repair was chosen. In case of an obscured VSD, TVD was the procedure of choice. The septal leaflet was detached from the annulus without injuring the aortic valve or the atrioventricular (AV) node (-Fig. 1B). In 34 patients (85\%), a double velour patch (Bard, Tempe, Arizona, United States) was used for VSD closure. The patches were sewn in place using 6-0 nylon (Premio, Péters, Bobigny, France) interrupted mattress or running sutures. In the remaining six patients, the defect was closed directly with 5-0 nylon mattress sutures (Prolene, Ethicon, Norderstedt, Germany). The TV incision was closed by either continuous or interrupted 6-0 nylon (Prolene, Ethicon, Norderstedt, Germany) sutures (-Fig. 1C). The competence of the valve was controlled by filling the right ventricle with cold saline and by quantifying the residual regurgitation. In case of significant regurgitation $(n=4$ : 3 no TVD and 1 TVD), a single suture stitch was performed approximating the anterior and septal leaflets.

\section{Statistics}

Statistical analysis was done with SPSS Version 22 (SPSS Inc., Chicago, Illinois, United States). Central tendency is expressed by mean and dispersion by standard deviation. Normal distribution was ruled out by the KolmogorovSmirnov's test for most parameters. Consequently, differences among groups were assessed using two-tailed
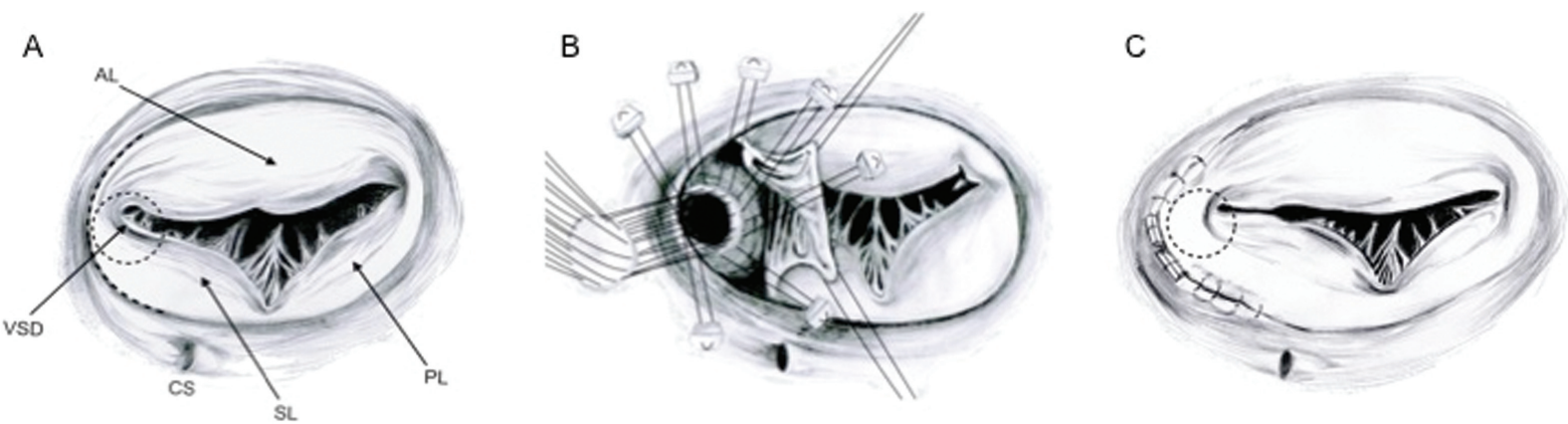

Fig. 1 Anteroseptal tricuspid valve detachment and technique of vSD closure. (A) The tricuspid valve is depicted with a VSD (dashed circle) obscured by tricuspid valve tissue and chordal attachments. The dashed line indicates the location of leaflet incision. (B) After annular incision and placement of retraction sutures, the VSD is exposed for closure. Interrupted pledgeted 6-0 mattress sutures are placed around the defect and a Dacron patch is tied into place. (C) The septal incision is closed with running 6-0 nylon sutures. AL, anterior leaflet; CS, coronary sinus; PL, posterior leaflet; SL, septal leaflet; VSD, ventricular septal defect. 
Table 1 Patient characteristics and perioperative data

\begin{tabular}{|l|l|l|l|}
\hline Characteristics & $\begin{array}{l}\text { TVD } \\
\text { Mean } \pm \text { SD }\end{array}$ & $\begin{array}{l}\text { No TVD } \\
\text { Mean } \pm \text { SD }\end{array}$ & $p$-Value \\
\hline Age (y) & $1.1 \pm 1.4$ & $0.7 \pm 0.5$ & 0.33 \\
\hline Weight $(\mathrm{kg})$ & $7.4 \pm 4.0$ & $6.2 \pm 2.2$ & 0.39 \\
\hline Height (cm) & $70.9 \pm 15.2$ & $65.0 \pm 9.9$ & 0.30 \\
\hline Gender (M/F) & $16 / 4$ & $10 / 10$ & 0.10 \\
\hline CPB time (min) & $123 \pm 48$ & $103 \pm 20$ & 0.10 \\
\hline $\begin{array}{l}\text { Cross-clamp } \\
\text { time (min) }\end{array}$ & $69 \pm 23$ & $54 \pm 16$ & 0.02 \\
\hline $\begin{array}{l}\text { Length of } \\
\text { postoperative } \\
\text { stay (d) }\end{array}$ & $10 \pm 4$ & $11 \pm 7$ & 0.93 \\
\hline $\begin{array}{l}\text { Length of ICU } \\
\text { stay (d) }\end{array}$ & $3 \pm 1$ & $4 \pm 4$ & 0.79 \\
\hline
\end{tabular}

Abbreviations: CPB, cardiopulmonary bypass; ICU, intensive care unit; SD, standard deviation; TVD, tricuspid valve detachment.

chi-square and Mann-Whitney's $\underline{U}$ tests. Intraindividual differences were assessed by Wilcoxon's test.

\section{Results}

Operative mortality was zero. There was no relevant operative or postoperative morbidity such as hemodynamically relevant residual shunt or permanent third-degree AV block.

\section{Patient Characteristics and Perioperative Data}

Demographic data are displayed in - Table 1. The pathoanatomy of the VSDs was perimembranous in $29(78 \%)$, inlet in 9 (17\%), and 2 (5\%) patients had muscular defects.

In the TVD group, 16 VSDs were perimembranous, and the remaining 4 were inlet VSDs. The two muscular defects were seen in the non-TVD group. In preoperative echocardiography, the most common findings besides the type of VSD were left atrial enlargement in 27 patients (44\%); left ventricular
(LV) enlargement in 17 (28\%); large, nonrestrictive VSD in 8 (13\%); aortic insufficiency in 5 (8\%); right ventricular enlargement in 3 (5\%); and endocarditis in $1(2 \%)$ patient.

The indication for surgery was congestive heart failure in $13(26 \%)$ patients, failure to thrive in 12 (24\%), volume overload with relative pulmonary stenosis in 18 (36\%), aortic insufficiency in 6 (12\%), and endocarditis in 1 (2\%) patient. In terms of demographic data and hospital/intensive care unit stay, both groups were comparable. The only exception was cross-clamp time $(69 \pm 5$ minutes for TVD and $54 \pm 4$ minutes for no TVD, $p=0.023$ ).

\section{Echocardiography}

The risk of TV regurgitation and AV block are the key issues of this technique. - Fig. $\mathbf{2}$ displays the degree of TR. Intraindividual comparison of the TVD and non-TVD cohort did not reveal a significant change in TR from preoperative to last follow-up ( $p=0.655$ and $p=1.000$, respectively). However, the comparison between preoperative and discharge data reveals that there is an obvious influence of the operation on TR. Nevertheless, this finding is outgrown over time. Preoperative systolic LV function was normal in 95\% and mildly impaired in 5\% each in both groups. At discharge, in the nonTVD group, it was normal in $90 \%$ and mildly impaired in $10 \%$; in the TVD group, it was normal in $80 \%$, mildly impaired in $5 \%$, and moderately impaired in $15 \%$ (intraindividual comparison to preoperative function: $p=0.567$ and $p=0.098$, respectively). At follow-up, it was normal in all patients in both groups (intraindividual comparison to preoperative function: $p=0.317$, both).

\section{Cardiac Biomarkers}

Cardiac biomarkers drawn 1 day postoperatively are shown in -Table 2. There were no significant differences between groups.

\section{Electrocardiogram}

Preoperatively, in the non-TVD group, there were six incomplete right bundle-branch blocks (RBBBs) (30\%) versus eight

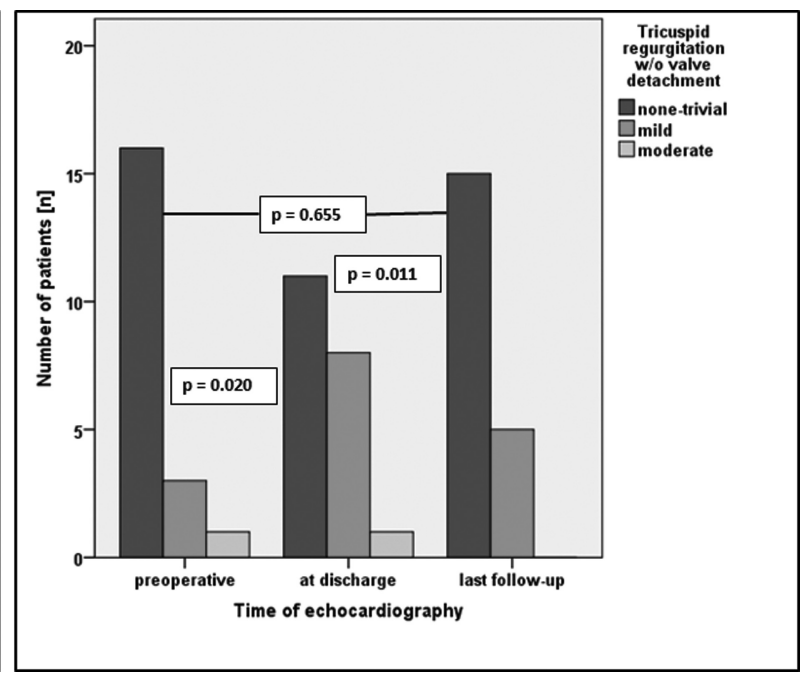

Fig. 2 Intraindividual comparison of tricuspid regurgitation preoperative, at discharge, and at latest follow-up. 
Table 2 Cardiac biomarkers on the first postoperative day

\begin{tabular}{|l|l|l|l|}
\hline Cardiac marker & $\begin{array}{l}\text { No TVD } \\
\text { Mean } \pm \text { SD }\end{array}$ & $\begin{array}{l}\text { TVD } \\
\text { Mean } \pm \text { SD }\end{array}$ & $p$-Value \\
\hline Troponin T (pg/mL) & $1,464 \pm 690$ & $1,833 \pm 965$ & 0.18 \\
\hline CK (U/L) & $740 \pm 284$ & $856 \pm 350$ & 0.25 \\
\hline CK-MB (U/L) & $75 \pm 38$ & $76 \pm 26$ & 0.92 \\
\hline MB (\%) & $12 \pm 9$ & $9 \pm 3$ & 0.19 \\
\hline
\end{tabular}

Abbreviations: CK, creatine kinase; $\mathrm{MB}$, muscle-brain type; SD, standard deviation.

(40\%) in the TVD group $(p=0.741)$. At follow-up, all patients were in sinus rhythm. There were no left bundle branch blocks. In the non-TVD group, there were 7 (35\%) complete RBBB and 5 (25\%) incomplete RBBB versus 3 (15\%) complete RBBB and $10(50 \%)$ incomplete RBBB in the TVD group $(p=0.191$ [incomplete RBBB]; $p=0.273$ [complete RBBB]). The TVD group included one patient who previously had a first-degree AV block and postoperatively developed a temporary third-degree AV block again followed by a permanent first-degree AV block.

\section{Discussion}

In surgical VSD closure, as in all procedures, exposure is the key to success. Particularly in VSDs, exposure can be cumbersome. This is mostly due to tricuspid chordal tissue or additional connective tissue in the area of the VSD. To avoid residual shunts after repair, some surgeons prefer to expose the VSD by partially detaching the septal leaflet of the TV. In addition to simply incising the septal and anterior leaflets parallel and close to the annulus, radial incision of the TV or detachment of the chordae from the septum is alternatives of exposing the VSDs. ${ }^{6,8,9}$ TVD primarily in the anterior leaflet could be advantageous in terms of AV block rate and is preferred by some surgeons whenever the situation allows. However, these methods are not univocally accepted as they may cause TR, alter the AV node, or prolong the whole procedure. An overview of the literature to this work is presented in - Table 3 .

Comparison of cross-clamp and CPB times shows contradictory results. Russell et al reported that the radial incision approach adds only little complexity to the procedure. Thus, cross-clamp and CPB times did not differ significantly. ${ }^{6}$ Other groups reported a significant longer cross-clamp time in the TVD group, but recommend to use it for better visualization whenever needed. ${ }^{21,22}$ Most groups investigating sequelae of the circumferential incision approach did not find a significant impact on AV block and TR and considered the technique as safe. In line with these results, our study shows that even partial annular detachment of the septal and anterior leaflets does not increase the risk of TR or conduction disorders in our cohort. Nevertheless, it is common knowledge that complete AV blocks after VSD closure occur. A sizeable multi-institutional study estimated the risk at roughly $1 \%$ for patients with an isolated perimembranous VSD. ${ }^{23}$ Furthermore, we found significantly more TR in both groups at discharge, which disappeared over time. Most likely, there is some structural rearrangement over time. Having this observation in mind, a much longer follow-up in the future is certainly of

Table 3 Summary of literature of patients undergoing tricuspid valve incision or detachment to expose anatomy for VSD closure (latest follow-up)

\begin{tabular}{|c|c|c|c|c|c|c|c|c|}
\hline First author & $\begin{array}{l}\text { Enrollment } \\
\text { period }\end{array}$ & $\begin{array}{l}\text { Patients } \\
\text { no. }\end{array}$ & $\begin{array}{l}\text { TVD } \\
(\%)\end{array}$ & $\begin{array}{l}\text { Heart } \\
\text { block }\end{array}$ & $\begin{array}{l}\text { Residual } \\
\text { VSD }\end{array}$ & $\begin{array}{l}\text { TR } \geq \\
\text { moderate }\end{array}$ & $\begin{array}{l}\text { Detached } \\
\text { leaflet }\end{array}$ & $\begin{array}{l}\text { Age }(y), \\
\text { mean }\end{array}$ \\
\hline Frenckner $^{10}$ & 1966-1979 & 27 & 18 & 0 & 0 & 0 & $\mathrm{SL}$ & $5^{a}$ \\
\hline Pridjian $^{11}$ & 1982-1993 & 40 & 100 & 0 & 0 & 0 & $\mathrm{SL}$ & $1.5^{\mathrm{a}}$ \\
\hline Tatebe $^{12}$ & 1981-1994 & 13 & 8 & 0 & 0 & 2 & SL/AL & $2.9^{\mathrm{a}}$ \\
\hline Gaynor $^{13}$ & 1996-1999 & 36 & 21 & 0 & 0 & 0 & $\mathrm{SL}$ & $0.5^{\mathrm{a}}$ \\
\hline Bol-Raap ${ }^{14}$ & 1985-1992 & 39 & 26 & 0 & 0 & 0 & SL/AL & 1.3 \\
\hline Zhao $^{15}$ & $1991-2001$ & 122 & 20 & 0 & 0 & 0 & $\mathrm{SL}$ & 4.6 \\
\hline $\operatorname{Lin}^{16}$ & 1997-2004 & 86 & 51 & 0 & 5 & 2 & $\mathrm{SL}$ & 6.7 \\
\hline Sasson $^{17}$ & $2000-2004$ & 41 & 23 & 0 & 0 & 0 & $\mathrm{SL}$ & 3.4 \\
\hline Scully ${ }^{18}$ & $2000-2006$ & 52 & 24 & 0 & 0 & 0 & $x$ & 0.8 \\
\hline Weymann $^{19}$ & 2004-2011 & 20 & 57 & 0 & 0 & 0 & $\mathrm{SL}$ & $0.5^{\mathrm{a}}$ \\
\hline Fraser $^{20}$ & $1997-2013$ & 83 & 34 & 0 & 0 & 1 & $\mathrm{SL}$ & $0.6^{\mathrm{a}}$ \\
\hline Bang $^{21}$ & 2004-2013 & 49 & 17 & 0 & 1 & 1 & SL/AL & $0.2^{\mathrm{a}}$ \\
\hline Current study & $2012-2015$ & 20 & 50 & 0 & 0 & 0 & $\mathrm{SL}$ & 1.1 \\
\hline Pourmoghadam ${ }^{9}$ & $2005-2016$ & 26 & 23 & 0 & 0 & 0 & $\mathrm{SL}$ & $0.6^{\mathrm{a}}$ \\
\hline Giordano 22 & $2008-2017$ & 11 & 7 & 0 & 0 & 1 & $\mathrm{SL}$ & 0.5 \\
\hline
\end{tabular}

Abbreviations: AL, anterior leaflet; SL, septal leaflet; TR, tricuspid regurgitation; TVD, tricuspid valve detachment; X, no data. aedian age. 
interest. CPB and aortic cross-clamping were longer in the TVD group because of the additional time needed to reattach the leaflets after VSD closure. However, for CPB, it did not reach a level of statistical significance and it is likely that the patients with TVD had principally the more difficult anatomies. Consequently, to facilitate better exposure and adequate visualization of the VSD and to thus guarantee a more sufficient closure, the cost of a prolonged operation time should be accepted. This study is limited by a somewhat small sample size and its retrospective nature. In addition, the fact that only two surgeons performed the operations by choice with or without TVD could further limit the interpretability of our study. It is likely that all VSDs could have been closed without TVD as well. However, experience and preference of the surgeon may play an important role. Based on our data, we recommend TVD as a valuable technique to visualize the entire (perimembranous and inlet) defect in selected cases.

\section{Note}

The study is part of the doctoral thesis of John Schittek at the University of Hamburg.

\section{Conflict of Interest \\ None declared.}

\section{Acknowledgment}

We thank Paul Schittek for the artwork.

\section{References}

1 van der Linde D, Konings EE, Slager MA, et al. Birth prevalence of congenital heart disease worldwide: a systematic review and meta-analysis. J Am Coll Cardiol 2011;58(21):2241-2247

2 Goor DA, Lillehei CW. Congenital Malformations of the Heart: Embryology, Anatomy, and Operative Considerations. 1st ed. Grune \& Stratton, New York, 1975

3 Muller WH Jr, Dammann JF Jr. The treatment of certain congenital malformations of the heart by the creation of pulmonic stenosis to reduce pulmonary hypertension and excessive pulmonary blood flow; a preliminary report. Surg Gynecol Obstet 1952;95 (02):213-219

4 Lillehei CW, Cohen M, Warden HE, Ziegler NR, Varco RL. The results of direct vision closure of ventricular septal defects in eight patients by means of controlled cross circulation. Surg Gynecol Obstet 1955;101(04):446-466

5 Hudspeth AS, Cordell AR, Meredith JH, Johnston FR. An improved transatrial approach to the closure of ventricular septal defects. J Thorac Cardiovasc Surg 1962;43:157-165

6 Russell HM, Forsberg K, Backer CL, Wurlitzer KC, Kaushal S, Mavroudis C. Outcomes of radial incision of the tricuspid valve for ventricular septal defect closure. Ann Thorac Surg 2011;92 (02):685-690, discussion 690

7 Zoghbi WA, Enriquez-Sarano M, Foster E, et al; American Society of Echocardiography. Recommendations for evaluation of the severity of native valvular regurgitation with two-dimensional and Doppler echocardiography. J Am Soc Echocardiogr 2003;16 (07):777-802

8 Kapoor L, Gan MD, Bandyhopadhyay A, Das MB, Chatterjee S. Improved exposure of isolated perimembranous ventricular septal defects. Ann Thorac Surg 2000;69(01):291-292

9 Pourmoghadam KK, Boron A, Ruzmetov M, et al. Septal leaflet versus chordal detachment in closure of hard-to-expose ventricular septal defects. Ann Thorac Surg 2018;106(03): 814-821

10 Frenckner BP, Olin CL, Bomfim V, Bjarke B, Wallgren CG, Björk VO. Detachment of the septal tricuspid leaflet during transatrial closure of isolated ventricular septal defect. J Thorac Cardiovasc Surg 1981;82(05):773-778

11 Pridjian AK, Pearce FB, Culpepper WS, Williams LC, Van Meter CH, Ochsner JL. Atrioventricular valve competence after takedown to improve exposure during ventricular septal defect repair. J Thorac Cardiovasc Surg 1993;106(06):1122-1125

12 Tatebe S, Miyamura H, Watanabe H, Sugawara M, Eguchi S. Closure of isolated ventricular septal defect with detachment of the tricuspid valve. J Card Surg 1995;10(05):564-568

13 Gaynor JW, O’Brien JE Jr, Rychik J, Sanchez GR, DeCampli WM, Spray TL. Outcome following tricuspid valve detachment for ventricular septal defects closure. Eur J Cardiothorac Surg 2001; 19(03):279-282

14 Bol-Raap G, Bogers AJ, Boersma H, De Jong PL, Hess J, Bos E. Temporary tricuspid valve detachment in closure of congenital ventricular septal defect. Eur J Cardiothorac Surg 1994;8(03): 145-148

15 Zhao J, Li J, Wei X, Zhao B, Sun W. Tricuspid valve detachment in closure of congenital ventricular septal defect. Tex Heart Inst J 2003;30(01):38-41

16 Lin YJ, Chang JP, Chien SJ, Liang CD, Huang CF, Kao CL. Novel method for evaluating tricuspid valve function after tricuspid valve detachment in the repair of perimembranous ventricular septal defects. Tex Heart Inst J 2012;39(06):806-810

17 Sasson L, Katz MG, Ezri T, et al. Indications for tricuspid valve detachment in closure of ventricular septal defect in children. Ann Thorac Surg 2006;82(03):958-963, discussion 963

18 Scully BB, Morales DL, Zafar F, McKenzie ED, Fraser CD Jr, Heinle JS. Current expectations for surgical repair of isolated ventricular septal defects. Ann Thorac Surg 2010;89(02):544-549, discussion 550-551

19 Weymann A, Georgiev S, Vogelsang C, et al. Temporary tricuspid valve detachment for ventricular septal defect closure: is it worth doing it? Heart Surg Forum 2013;16(02):E99-E102

20 Fraser CD III, Zhou X, Palepu S, et al. Tricuspid valve detachment in ventricular septal defect closure does not impact valve function. Ann Thorac Surg 2018;106(01):145-150

21 Bang JH, Park CS, Park JJ, et al. Detachment of the tricuspid valve for ventricular septal defect closure in infants younger than 3 months. J Thorac Cardiovasc Surg 2016;152(02):491-496

22 Giordano R, Cantinotti M, Di Tommaso L, et al. The fate of the tricuspid valve after the transatrial closure of the ventricular septal defect. Ann Thorac Surg 2018;106(04):1229-1233

23 Tucker EM, Pyles LA, Bass JL, Moller JH. Permanent pacemaker for atrioventricular conduction block after operative repair of perimembranous ventricular septal defect. J Am Coll Cardiol 2007;50 (12):1196-1200 